\title{
Gastroesophageal Reflux Disease (GERD) - Role of Dentist
}

\author{
Anupama Aradya ${ }^{1}$, Raghavendra Swamy Koodalakuppe Nagarajagowda ${ }^{2}$, Aradya Hiriyannaiah Venu ${ }^{3}$, \\ Sowmya Srinivas ${ }^{4}$, Ganesh Somashekara Char ${ }^{5}$, Meenakshi Srinivasa Iyer ${ }^{6}$
}

1, 2, 4, 5, 6 Department of Prosthodontics, JSS Dental College and Hospital, A Constituent College of JSS Academy of Higher Education \& Research, Mysuru, Karnataka, India, ${ }^{3}$ Department of Gastroenterology, JSS Medical College and Hospital, A Constituent College of JSS Academy of Higher Education \& Research, Mysuru, Karnataka, India.

\section{ABSTRACT}

\section{BACKGROUND}

Gastroesophageal reflux disease (GERD) is highly prevalent across populations with varied manifestations and substantial morbidity. Our review focuses mainly on the role of dental practitioner in GERD, its oral manifestations and management. GERD shows oesophageal and extra oesophageal syndromes. Oesophageal syndromes are reflux chest pain syndrome, typical reflux syndrome, reflux stricture, reflux esophagitis, oesophageal adenocarcinoma and Barrett's oesophagus. Extra oesophageal syndromes are reflux cough syndrome, reflux asthma syndrome, reflux dental erosion syndrome, reflux laryngitis syndrome, pharyngitis, and sinusitis. Classic reflux symptoms may be absent in more than half the patients presenting with extra oesophageal symptoms. For this reason, the first provisional diagnosis of GERD may be made by a dental practitioner as a result of clinical observation of enamel erosion. A direct association exists between gastroesophageal reflux disease and oral cavity diseases. Dental practitioner can recognise the secondary manifestations of GERD for early diagnosis and can assist in management of these patients. Traditional management of GERD includes medical therapy, non-medical therapy and surgical therapy, in future dental examination and dental treatment can also be included. There is a lack of awareness among the general physicians regarding the association between GERD and dental erosions. According to the study, $40 \%$ of them are aware of dental erosions in GERD, indicating that there is a need to circulate this information through medical education.

There should be an interdisciplinary coordination between family physician, dentist, orthodontist, prosthodontist, and gastroenterologist for treatment of oral manifestations resulting from GERD. This review highlights the role of dental practitioner in management of GERD.

\section{KEY WORDS}

Gastro Oesophageal Reflux Disease (GERD), Dental Erosion, Oesophagus, Gastric acid, Saliva
Corresponding Author: Dr. Aradya $H V M D, D N B$ Assistant professor, Department of Gastroenterology, JSS Medical College and Hospital, A Constituent College of JSS Academy of Higher Education \& Research Mysuru, Karnataka, India. E-mail: aradyahv@jssuni.edu.in

DOI: $10.14260 /$ jemds/2021/412

How to Cite This Article: Aradya A, Nagarajagowda RSK, Venu AH, et al. Gastroesophageal reflux disease (GERD) - role of dentist. J Evolution Med Dent Sci 2021;10(27):2012-2017, DOI: 10.14260/jemds/2021/412

Submission 25-01-2021,

Peer Review 03-05-2021,

Acceptance 10-05-2021,

Published 05-07-2021.

Copyright (c) 2021 Anupama Aradya et al. This is an open access article distributed under Creative Commons Attribution License [Attribution 4.0 International (CC BY 4.0)] 


\section{BACKGROUND}

Gastro oesophageal reflux is a normal physiological process that is present in healthy infants, children and adults. ${ }^{1}$ Gastroesophageal reflux disease has been seen historically as a disease of western countries and was thought to be distinctly uncommon among Asians. ${ }^{2}$ However endoscopic studies and more recently symptom based surveys have shown that reflux disease is more common in Asia than previously recognised. ${ }^{3}$ Classical symptoms of GERD are regurgitation, heartburn, nausea, or respiratory problems like asthma, wheezing, coughing and its oesophageal complications. Dental erosion, as an extra esophageal manifestations of GERD has been reported with varying prevalence in the population and may be as high as $42 \%{ }^{4}$ This article provides an overview of aspects of GERD, its oral manifestations and management.

\section{GASTROESOPHAGEAL REFLUX DISEASE} (GERD)

\section{Definition}

Gastro oesophageal reflux (GER) is defined as the passage of gastric contents into the oesophagus. GERD is a consequence of failure of the normal anti reflux barrier to protect against frequent and abnormal amounts of refluxed material. GER itself is not a disease and occurs multiple times each day without producing symptoms or mucosal damage, where as GERD is characterized by signs or complications of GER. ${ }^{5}$ The most widely accepted criterion for diagnosis of GERD is the happening of heartburn two or more times each week.

\section{Pathogenesis}

The pathogenesis of GERD is complex, resulting from an imbalance between defensive factors protecting the oesophagus (oesophageal acid clearance, tissue resistance) and aggressive factors refluxing from the stomach (gastric acidity, volume, and duodenal contents).

\section{PATHOPHYSIOLOGICAL CONCEPTS}

Gastro-oesophageal reflux may trigger extra-oesophageal manifestations in the upper and lower respiratory tract via two basic pathways 6

1. Reflux of gastric contents into the pharynx with or without aspiration into the deeper airways. In addition, the aspirate can increase the sensitivity of the airway mucosa to other triggers.

2. Reflux of acid gastric content into the lower oesophagus triggers airway symptoms, such as cough and bronchospasm, via vagal reflex arcs.

The drugs frequently used to treat obstructive airway diseases, such as theophylline and beta agonist, may affect the pressure gradient across the anti-reflux barrier and the pressure of the lower oesophageal sphincter. This in turn may lead to increased gastro-oesophageal reflux. ${ }^{\text {? }}$

\section{AETIOLOGY}

\section{Gastric Factors}

Patients with GERD have delayed acid clearance. Gastroparesis, increased abdominal distension and myopathy affecting gastro intestinal motility are all aetiologic agents in GERD. ${ }^{8}$ The other causative factors are some drugs like calcium - channel blockers, nitrates and cigarette smoking.

In addition dysfunction of the upper oesophageal sphincter (UES), which normally increases its pressure when minute amounts of gastric fluid are in contact with the pharynx to protect upper airway from further exposure, may have an important role in the aetiology of extra-oesophageal manifestations. ${ }^{9}$

\section{Clinical Features}

GERD shows oesophageal and extra oesophageal syndromes. Oesophageal syndromes are reflux chest pain syndrome, typical reflux syndrome, reflux stricture, reflux esophagitis, oesophageal adenocarcinoma and Barrett's oesophagus. Extra oesophageal syndromes are reflux cough syndrome, reflux asthma syndrome, reflux dental erosion syndrome, reflux laryngitis syndrome, pharyngitis, sinusitis, idiopathic pulmonary fibrosis and recurrent otitis media. ${ }^{10}$ Additional signs of GERD include chronic laryngitis, gastric fluid in the oral cavity, laryngeal granuloma, laryngeal carcinoma, chronic pharyngitis, subglottic stricture, vocal cord polyps. Classic reflux symptoms may be absent in more than half the patients presenting with extra oesophageal symptoms. For this reason, the first provisional diagnosis of GERD may be made by a dental practitioner as a result of clinical observation of enamel erosion. ${ }^{11}$

\section{Complications}

The complications include Barrett's oesophagus, oesophageal stenosis, ulcer in the oesophagus, increased risk of transformation to oesophageal adenocarcinoma, pulmonary aspiration and upper gastrointestinal haemorrhage. ${ }^{12}$

\section{Diagnosis}

The diagnosis is typically made by a combination of clinical signs and symptoms, response to acid suppression, as well as objective testing with upper endoscopy and monitoring of oesophageal pH.13 (Table 1)

\begin{tabular}{|cc|}
\hline $\begin{array}{c}\text { Diagnostic Test } \\
\text { PPT trial } \\
\text { Oesophageal ph. } \\
\text { monitoring }\end{array}$ & For definitive GERD symptoms \\
$\begin{array}{c}\text { Upper endoscopy } \\
\text { Garium esophagram diagnosis is in question with refractory symptoms } \\
\text { Alarm symptoms (like dysphagia), PPI insensitive } \\
\text { patients, most at risk for Barret's oesophagus }\end{array}$ \\
$\begin{array}{c}\text { High resolution } \\
\text { manometry }\end{array}$ & $\begin{array}{c}\text { Prior to anti - reflux surgery to rule out esophageal } \\
\text { Gysmotility (eg.,achalasia, scleoroderma) or else not } \\
\text { recommended for GERD evaluation }\end{array}$ \\
\hline Table 1. Diagnostic Testing for Gastro Oesophageal Reflux Disease \\
\hline
\end{tabular}




\section{Treatment}

GERD requires long- term management in the form of non medical therapy, medical therapy and surgical therapy. Non medical therapy includes lifestyle and diet modification, head of bed elevation, avoiding night time meals, and elimination of trigger foods like caffeine, chocolate and alcohol. ${ }^{14}$ Medical therapy includes acid neutralizing agents, Histamine -2 blockers, enteric emptying pro kinetic agents, proton pump inhibitors. ${ }^{15}$ (Table 2)

\begin{tabular}{|c|c|c|}
\hline Therapy & Agent & Dosage \\
\hline $\begin{array}{l}\text { Acid - neutralizing agents } \\
\text { for GERD }\end{array}$ & $\begin{array}{l}\text { Sodium bicarbonate } \\
\text { (NaHCO3) } \\
\text { Magnesium hydroxide } \\
\text { (milk of magnesia) } \\
\text { Aluminates }\end{array}$ & $\begin{array}{c}1 \text { suppository PR } 325-650 \mathrm{mg} \\
\text { PO } \\
1.8-14.4 \mathrm{~g} \mathrm{qd} \\
15-45 \mathrm{~mL} \mathrm{q} 3-6 \mathrm{~h}\end{array}$ \\
\hline Histamine - 2 blockers & $\begin{array}{l}\text { Cimetidine } \\
\text { Ranitidine } \\
\text { Famotidine }\end{array}$ & $\begin{array}{c}800 \mathrm{mg} \mathrm{PO} \text { hs } 400 \mathrm{mg} \text { bid } \\
300 \mathrm{mg} \text { PO hs } 150 \mathrm{mg} \text { bid } \\
20 \mathrm{mg} \text { PO bid } \\
150 \mathrm{mg} \text { PO bid }\end{array}$ \\
\hline Gastric emptying & Metoclopramide & $\begin{array}{c}10-20 \mathrm{mg} \text { PO, IM or IV } \\
\text { (IV given over } 1-2 \mathrm{~min} \text { ) }\end{array}$ \\
\hline Prokinetic agents & Cisapride & $10-20 \mathrm{mg}$ PO qid \\
\hline Proton pump inhibitors & $\begin{array}{l}\text { Omeprazole } \\
\text { Lansoprazole }\end{array}$ & $20-40 \mathrm{mg}$ qd every morning \\
\hline \multicolumn{3}{|c|}{ Table 2. Medical Therapy for Gastroesophageal Reflux Disease } \\
\hline $\begin{array}{l}\mathrm{PR}=\text { per rectum, } \mathrm{PO}=\mathrm{F} \\
\mathrm{hs}=\text { at bedtime, } \mathrm{bid}=2 \\
\text { qid }=4 \text { times daily }\end{array}$ & $\begin{array}{l}\text { er os, } q d=\text { every day, } \\
\text { times daily, IM = intr }\end{array}$ & $\begin{array}{l}\mathrm{q} 3-6 \mathrm{~h}=\text { every } 3-6 \text { hours } \\
\text { amuscular, } \mathrm{IV}=\text { intravenous }\end{array}$ \\
\hline
\end{tabular}

\section{Surgical Therapy}

Surgical therapy is another treatment option for long term therapy in patients with GERD. Surgery indications include unwillingness to remain on lifelong medical therapy, intolerance of medical therapy, evidence of GERD endoscopy or $\mathrm{pH}$ monitoring. ${ }^{14}$ The fundamental requirement for a successful treatment of GERD is a multidisciplinary approach involving general practitioners, gastroenterologists, otorhinolaryngologists. Dentists can support the medical management of GERD patients by recognising the secondary manifestations of GERD and directing the patient towards further management. ${ }^{16}$

\section{ROLE OF DENTIST IN GERD}

\section{Dental Erosion}

Oral manifestations can be an indicator for GERD. ${ }^{17}$ Dental erosion is characterised as irreversible loss of dental hard tissue by a combination procedure that doesn't include microscopic organisms. Dissolution of mineralized tooth structure occurs upon contact with acids that are introduced into the oral cavity from intrinsic or extrinsic sources. ${ }^{18}$

\section{Prevalence}

The prevalence of dental erosion varies widely and depends upon age - 6 - $50 \%$ in pre-school children, $11-100 \%$ in adolescents, 4 - $82 \%$ in Adults. ${ }^{19}$

\section{Pathogenesis}

The mechanism producing dental erosion starts at the surface of the dental tissue, where the chelating agents or decalcifying acid destroy the pellicle, followed by the dissolution of the tooth's organic substrate and the demineralization of the surface. The damaged dental surface is exposed to mechanical friction in connection with chewing, swallowing, mobilizing the soft tissues or brushing. These losses may affect hard tissues, the enamel and the dentin. The erosion areas have a smooth, concave and lacunary appearance. ${ }^{20}$

\section{Aetiology}

\section{Extrinsic Erosion}

Teeth are regularly exposed to exogenous acids, such as fruit drink, soft drinks, pickles, fresh fruits, and yogurt; most of these foods present an acidic environment causing enamel demineralization. ${ }^{21}$

\section{Intrinsic Erosion}

The major cause is Gastroesophageal reflux. ${ }^{22}$ Teeth are affected by endogenous acids during recurrent vomiting, regurgitation, or reflux. To decide the aetiological variables of dental erosion, the dental specialist should acquire details from the patient regarding his / her recreations and work. ${ }^{23}$

\section{Biological Modifying Factors}

The factors affecting erosion process are saliva, tooth composition, tooth structure, dental anatomy, soft tissue anatomy and occlusion. The buffering capacity of saliva and unstimulated salivary flow rate have been directly linked with dental erosion. The pellicle function is to protect against acid demineralization. ${ }^{24}$ Any procedure which eliminates the pellicle thickness may lead to loss of protective properties and accelerate erosion process. The content of saliva like Matrix metallo proteinases (MMPs) have been recently involved in the progression of erosion.

\begin{tabular}{|cc|}
\hline Grade & Description \\
Zero & Tooth erosion is not visible \\
One & $\begin{array}{c}\text { Preservation of occlusal surface structure, lightly rounded and flattened } \\
\text { cusps with moderate cupping, small occlusal pits and fissures. } \\
\text { Restoration margins are seen above the level of surrounding tooth. } \\
\text { Two } \\
\text { Flattening of cusps with severe cupping and occlusal surface structure, } \\
\text { grooving and flattening }\end{array}$ \\
\hline & Table 3. Dental Erosion Evaluation Scale of Ganss \\
\hline
\end{tabular}

\begin{tabular}{|cc|}
\hline $\begin{array}{c}\text { Grade } \\
\text { Zero }\end{array}$ & Description \\
One & No tooth disintegration \\
Two & Less than one third of the crown is affected; disintegration is confined \\
to the dentin. \\
Three & More than one third of the crown is affected; disintegration is confined \\
to the dentin.
\end{tabular}

\section{Clinical Features}

The primary signs of dental erosion are: absence of macroscopic plaque; diminishing enamel luster; Due to loss of microanatomy, the dental surfaces becomes rounded and polished, smoothening out of developmental pits and grooves, dentin exposure, prominent restorations that are elevated above the surrounding tooth structure are seen. Proximal ridges gradually become flat and even concave. ${ }^{25}$ The most common site of dental erosion is on the palatal surface. (Table 3 and Table 4).

\section{Diagnosis Protocol}

A thorough dental evaluation including individual's clinical history, type of diet intake and oral hygiene techniques, additionally an intraoral assessment, salivary capacity, head and neck examination are to be done. ${ }^{26}$ 


\section{Medical History}

Clinical assessment starts with a complete medical history, including history of vomiting, gastric reflux signs, examination of gastro-intestinal structures, and a listing of all nonprescription medications. Use of $\beta 2$ - agonists, for example, salbutamol, salmeterol, or terbutaline, prompts diminished salivary stream, resulting in lessening of defensive impacts of saliva. ${ }^{27}$ Broncho dilators act to loosen up the smooth muscle and they may influence the oesophageal sphincter and thereby increase the gastro oesophageal reflux. Vitamin $\mathrm{C}$ tablets chewing shall cause a pH under 2.0 in the mouth, leading to drop in saliva ph. The assessment should include enquiries regarding the acidic taste for the mouth, burping, indigestion, coughing, unconstrained spewing, halitosis, and excessive salivation. On the off chance that a dental specialist is dubious about a patient may have gastric reflux, he should refer patient for additional clinical assessment.

\section{Dietary History}

The dental specialist should get the definite information about diet history to decide the aetiological components of dental erosion and to apply sufficient preventive measures. The recurrence of utilization of acidic beverages (sodas, natural product juices, sport beverages) and specific nourishments (citrus organic products) are significant factors in tooth erosion, ${ }^{28}$ since they contain acids.

\section{Occupational History}

Regular contact with acids in the work spot can rise the severity of dental erosion. In a study by Geurtsen, ${ }^{29}$ rigorous swimmers show increased incidence of dental erosion because of low $\mathrm{pH}$ gas - chlorinated pool water.

\section{Intraoral Examination}

Changes in teeth shading and sensitivity may give several details about lesions. ${ }^{30}$ Classic indications of enamel erosion are the presence of a smooth, plush coated, sometimes dull enamel surface with the perikymata nonappearance. ${ }^{30}$ In further developed phases of dental erosion, the morphology changes and brings about a concavity in the enamel, the width of which obviously surpasses its depth. ${ }^{16}$ Extrinsic erosion happens fundamentally on the anterior teeth labial surfaces, posterior teeth buccal surfaces and molar teeth occlusal surfaces. Refluxed acid first attack upper incisor palatal surfaces; in the auxiliary stage, posterior teeth occlusal surfaces of both the arches are affected. The palatal surfaces of the maxillary teeth are first influenced because of the way that they are shielded from the major salivary organs, and the tongue keeps in touch with the gastric acid. Experts have inferred that the force of the regurgitation flowing from the pharynx into the mouth may impact the seriousness of dental erosion.

\section{Dental History}

The tooth structure area surrounding the restorations dissolve appreciably more quickly than the restorative material.

\section{Salivary Function}

The salivary $\mathrm{Ph}$ and the buffering limit can be determined with an indicator system in recently collected saliva. Chewing will rise the flow rate and the buffering limit of saliva. ${ }^{31}$

\section{Management of Erosion in GERD}

Preventive Treatment

There is a lack of awareness among the general physicians regarding the association between GERD and dental erosions. According to the study, $40 \%$ of them are aware of dental erosions in GERD, indicating that there is a need to circulate this information through medical education.

Dental specialists and patients should know about acidic attack that may irreversibly harm the dental hard tissue. First and fore most is to reduce the extent of oral acidity to anticipate erosive attacks. For people at higher danger of dental erosion, it is wise to decrease the frequency of intake of possible harmful beverages and food and limiting their contact time with teeth. ${ }^{32}$ Sugar free antacid medications chewing will help to enhance salivary flow rates and lessen the acidity too. Immediately after sensation of acid reflux into the mouth patients can take antacids. Patients with erosion should be taught to rinse the mouth with sodium carbonate, a fluoride mouthwash and water, following a noteworthy acid test. Fluoride mouthwash will help to remineralize the abraded tooth structure surface. Individuals must be taught not to use more abrasive toothpastes. Fluoride varnish ought to be applied at regular intervals

\section{Recent Advances}

As of late, the laser application has defensive influence on enamel and dentin demineralization. Laser application dissolves and solidifies the dental surface, making another, smoother surface. ${ }^{33}$ Casein phosphopeptide / amorphous calcium phosphate (CPP - ACP) are used to decrease dental erosion. Amorphous calcium phosphate ought to be applied daily by rubbing it on the teeth with a finger or utilizing a bleaching tray. Nd:YAG laser and its relationship with fluoride have been proposed as a possibility for the treatment of dental erosion. Additionally, resin based dentine bonding agents has been accounted for the protection of dentin. During high danger of erosive challenge, such as during rest (for patients with reflux) a close fitting occlusal guard can be utilized.

To enhance the rates of salivary flow in patients with erosion, use of sugar - free antacids and xylitol chewing gum should be encouraged. Xylitol promotes mineralization by increasing the salivary flow and by defeating the growth, metabolism, and polysaccharide production of streptococci mutans. ${ }^{34}$

\section{Restorative Treatment}

Patients with chronic regurgitation and acid reflux symptoms present for at least two days should be suggested to visit a doctor for additional examination, as the untreated condition can prompt complexities, like erosive esophagitis and Barrett's oesophagus which enhances the danger of oesophageal adenocarcinoma. ${ }^{35}$ Some of the patients may not know about their condition as disease till it begins influencing their teeth. These patients should consult an appropriate expert or a multidisciplinary group.

The dental specialist should consider remedial treatment when -

1. Structural integrity of affected teeth are impeded;

2. The hypersensitive teeth; 
3. Loss of vertical dimension, function as well as its structure;

4. Unacceptable aesthetics and

5. Exposure of pulp.

Initially, erosion is constrained to the enamel during which phase the teeth are not hypersensitive. Restorations of teeth are required for aesthetic needs as well as to prevent further progression. In advanced cases, restoration of tooth form with direct composite coatings or porcelain veneers should be considered as treatment of choice.

Indirect restorations (ceramic crown bridges) are indicated for patients with loss of vertical dimension and severely destructed teeth.

\section{Recommendations for Patients with GERD}

1. For a definitive diagnosis and treatment, patients should be examined by a physician.

2. Instantly after heartburn or sensation of acid reflux into the mouth, take antacids.

3. Rinse the mouth with water, sodium bicarbonate, and a fluoride mouthwash immediately after a noteworthy acid challenge.

4. Abstain from brushing teeth following an acid challenge and use of abrasive toothpastes.

5. Decrease the utilization of acidic and carbonated drinks.

6. To stimulate salivary flow use xylitol chewing gum.

7. During high risk erosive challenge viz during sleep use a close fitting occlusal guard.

8. Use desensitizing and fluoride toothpaste. ${ }^{36}$

\section{CONCLUSIONS}

There is a close relationship between GERD and oral cavity diseases. The secondary manifestations of GERD can be recognised early by otorhinolaryngologists, gastroenterologists and dentists. Management of GERD should also include a dental examination with acceptable dental remedy. Multidisciplinary approach involving family physician, dentist, orthodontist, prosthodontist, and gastroenterologist is required for the treatment of dental erosion resulting from GERD. Most of the dental erosion patients who take treatment have been referred, by both physicians and the family dentists. This template reflects that both dentists and gastroenterologists are mainly the first health care providers to diagnose GERD based on its oral manifestations.

Financial or other competing interests: None.

Disclosure forms provided by the authors are available with the full text of this article at jemds.com.

\section{REFERENCES}

[1] Colletti RB, Di Lorenzo C. Overview of pediatric gastroesophageal reflux disease and proton pump inhibitor therapy. J Pediatr Gastroenterol Nutr 2003;37(Suppl 1):S7-11.
[2] Goh KL. Changing epidemiology of gastroesophageal reflux disease in the Asian-Pacific region: an overview. J Gastroenterol Hepatol 2004;19(3):S22-5.

[3] Wong BCY, Kinoshita Y. Systematic review on epidemiology of gastroesophageal reflux disease in Asia. Clin Gastroenterol Hepatol 2006;4(4):398-407.

[4] Alfaro EV, Aps JK, Martens LC. Oral implications in children with gastroesophageal reflux disease. Curr Opin Pediatr 2008;20(5):576-83.

[5] Rudolph CD, Mazur LJ, Liptak GS, et al. Guidelines for evaluation and treatment of gastroesophageal reflux in infants and children: recommendations of the North American Society for Pediatric Gastroenterology and Nutrition. J Pediatr Gastroenterol Nutr 2001;32 (Suppl 2):S1-31.

[6] Adhami T, Goldblum JR, Richter JE, et al. The role of gastric and duodenal agents in laryngeal injury: an experimental canine model. Am J Gastroenterol 2004;99(11):2098-106.

[7] Bartlett DW, Evans DF, Anggiansah A, et al. The role of the esophagus in dental erosion. Oral Surg Oral Med Oral Pathol Oral Radiol Endod 2000;89(3):312-5.

[8] Bartlett D, Smith B. Clinical investigations of gastrooesophageal reflux: Part 1. Dent Update 1996;23(5):2058.

[9] Ulualp So, Toohill RJ, Kern M, et al. Pharyngo-UES contractile reflex in patients with posterior laryngitis. Laryngoscope 1998;108(9):1354-7.

[10] Labenz J. Facts and fantasies in extra-oesophageal symptoms in GORD. Best Pract Res Clin Gastroenterol 2010;24(6):893-904.

[11] Ali DA, Brown RS, Rodríguez LO, et al. Dental erosion caused by silent gastroesophageal reflux disease. J Am Dent Assoc 2002;133(6):734-7.

[12] Friedman LS, Peterson WL. Peptic ulcer and related disorders. In: Fauci AS, Braunwald E, Isselbacher KJ, et al, eds. Harrison's principles of internal medicine. $14^{\text {th }}$ edn. USA: Mcgraw Hill 1998.

[13] Tefera L, Fein M, Ritter MP, et al. Can the combination of symptoms and endoscopy confirm the presence of gastroesophageal reflux disease? Am Surg 1997;63(10):933-6.

[14] Badillo R, Francis D. Diagnosis and treatment of gastroesophageal reflux disease. World J Gastrointest Pharmacol Ther 2014;5(3):105-12.

[15] Demeester TR, Johnson LF, Joseph GJ, et al. Patterns of gastroesophageal reflux in health and disease. Ann Surg 1976;184(4):459-69.

[16] Petruzzi M, Lucchese A, Campus G, et al. Oral stigmatic lesions of gastroesophageal reflux disease (GERD). Rev Med Chil 2012;140(7):915-8.

[17] Bartlett DW, Evans DF, Smith BG. Oral regurgitation after reflux provoking meals: a possible cause of dental erosion? J Oral Rehabil 1997;24(2):102-8.

[18] Sivapathasundharam B. Shafer's textbook of oral pathology. 8 $^{\text {th }}$ edn. India: Elsevier 2016.

[19] Lussi A, Hellwig E, Zero D, et al. Erosive tooth wear: diagnosis, risk factors and prevention. Am J Dent 2006;19(6):319-25.

[20] Picos A, Chisnoiu A, Dumitrasc DL. Dental erosion in patients with gastroesophageal reflux disease. Adv Clin Exp Med 2013;22(3):303-7.

[21] Moss SJ. Dental erosion. Int Dent J 1998;48(6):529-39. 
[22] Cardoso AC, Canabarro S, Myers SL. Dental erosion: diagnostic-based noninvasive treatment. Pract Periodontics Aesthet Dent 2000;12(2):223-8.

[23] Dundar A, Sengun A. Dental approach to erosive tooth wear in gastroesophageal reflux disease. Afr Health Sci 2014;14(2):481-6.

[24] Zahradnik RT, Moreno EC, Burke EJ. Effect of salivary pellicle on enamel subsurface demineralization in vitro. J Dent Res 1976;55(4):664-70.

[25] Ganss C. Definition of erosion and links to tooth wear. In: Lussi A, ed. Dental erosion: from diagnosis to therapy. Bern: Karger 2006:9-16.

[26] Gandara BK, Truelove EL. Diagnosis and management of dental erosion. J Contemp Dent Pract 1999;1(1):16-23.

[27] Hellwig E, Lussi A. Oral hygiene products and acidic medicines. Monogr Oral Sci 2006;20:112-8.

[28] Magalhaes AC, Wiegand A, Rios D, et al. Insights into preventive measures for dental erosion. J Appl Oral Sci 2009;17(2):75-86.
[29] Geurtsen W. Rapid general dental erosion by gaschlorinated swimming pool water. Review of the literature and case report. Am J Dent 2000;13(6):291-3.

[30] Lussi A, Jaeggi T. Erosion--diagnosis and risk factors. Clin Oral Investig 2008;12(Suppl 1):5-13.

[31] Edgar WM. Saliva and dental health. Clinical implications of saliva: report of a consensus meeting. Br Dent J 1990;169(3-4):96-8.

[32] Imfeld T. Dental erosion. Definition, classification and links. Eur J Oral Sci 1996;104(Pt 2):151-5.

[33] Soderling EM. Xylitol, mutans streptococci and dental plaque. Adv Dent Res 2009;21(1):74-8.

[34] Howden CW, Chey WD. Gastroesophageal reflux disease. The Journal of Family Practice 2003;52(3):240-7.

[35] Jaeggi T, Gruninger A, Lussi A. Restorative therapy of erosion. Monogr Oral Sci 2006;20:200-14.

[36] Dundar A, Sengun A. Dental approach to erosive tooth wear in gastroesophageal reflux disease. Afr Health Sci 2014;14(2):481-6. 